\title{
Hybrid metallic nanocomposites for extra wear-resistant diamond machining tools
}

\author{
Loginov, P.A. ; Sidorenko, D.A.; Levashov, E.A.; Petrzhik, M.I.; Bychkova, M.Ya.; Mishnaevsky, Leon
}

Published in:

International Journal of Refractory Metals and Hard Materials

Link to article, DOI:

10.1016/j.ijrmhm.2017.10.017

Publication date:

2018

Document Version

Peer reviewed version

Link back to DTU Orbit

Citation (APA):

Loginov, P. A., Sidorenko, D. A., Levashov, E. A., Petrzhik, M. I., Bychkova, M. Y., \& Mishnaevsky, L. (2018). Hybrid metallic nanocomposites for extra wear-resistant diamond machining tools. International Journal of Refractory Metals and Hard Materials, 71, 36-44. https://doi.org/10.1016/j.ijrmhm.2017.10.017

\section{General rights}

Copyright and moral rights for the publications made accessible in the public portal are retained by the authors and/or other copyright owners and it is a condition of accessing publications that users recognise and abide by the legal requirements associated with these rights.

- Users may download and print one copy of any publication from the public portal for the purpose of private study or research.

- You may not further distribute the material or use it for any profit-making activity or commercial gain

- You may freely distribute the URL identifying the publication in the public portal 


\section{Accepted Manuscript}

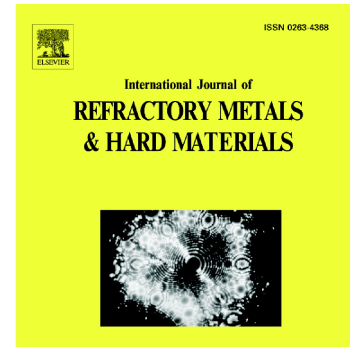

P.A. Loginov, D.A. Sidorenko, E.A. Levashov, M.I. Petrzhik, M.Ya. Bychkova, L. Mishnaevsky

PII: $\quad$ S0263-4368(17)30656-X

DOI: $\quad$ doi:10.1016/j.ijrmhm.2017.10.017

Reference: $\quad$ RMHM 4543

To appear in: International Journal of Refractory Metals and Hard Materials

Received date: 20 September 2017

Revised date: $\quad 17$ October 2017

Accepted date: 24 October 2017

Please cite this article as: P.A. Loginov, D.A. Sidorenko, E.A. Levashov, M.I. Petrzhik, M.Ya. Bychkova, L. Mishnaevsky, Hybrid metallic nanocomposites for extra wearresistant diamond machining tools. The address for the corresponding author was captured as affiliation for all authors. Please check if appropriate. Rmhm(2017), doi:10.1016/ j.ijrmhm.2017.10.017

This is a PDF file of an unedited manuscript that has been accepted for publication. As a service to our customers we are providing this early version of the manuscript. The manuscript will undergo copyediting, typesetting, and review of the resulting proof before it is published in its final form. Please note that during the production process errors may be discovered which could affect the content, and all legal disclaimers that apply to the journal pertain. 


\title{
HYBRID METALLIC NANOCOMPOSITES FOR EXTRA WEAR- RESISTANT DIAMOND MACHINING TOOLS
}

\author{
P.A. Loginov ${ }^{1}$, D.A. Sidorenko ${ }^{1}$, E.A. Levashov ${ }^{1}$, M.I. Petrzhik ${ }^{1}$, M.Ya. Bychkova ${ }^{1}$, L. \\ Mishnaevsky Jr. ${ }^{2}$ \\ ${ }^{1}$ National University of Science and Technology "MISIS", Moscow 119049, Russia, \\ ${ }^{2}$ Department of Wind Energy, Technical University of Denmark, Roskilde, Denmark
}

\begin{abstract}
:
The applicability of metallic nanocomposites as binder for diamond machining tools is demonstrated. The various nanoreinforcements (carbon nanotubes, boron nitride hBN, nanoparticles of tungsten carbide/WC) and their combinations are embedded into metallic matrices and their mechanical properties are determined in experiments. The wear resistance of diamond tools with metallic binders modified by various nanoreinforcements was estimated. 3D hierarchical computational finite element model of the tool binder with hybrid nanoscale reinforcements is developed, and applied for the structure-properties analysis of the binder. It is shown that the metallic nanocomposites with hybrid reinforcements ensure the highest mechanical properties and also the highest wear-resistance of the machining tools, with the nanocomposites used as binder.
\end{abstract}

Keywords: Composites; Nanocomposites; Machining tool; Carbon nanotubes; 


\section{Introduction}

Diamond machining tools play a crucial role in large-scale industrial processing of various materials, such as natural stone, concretes, asphalt and steels [1]. The tools represent in fact composite materials [2], with synthetic diamond grains incorporated into the metal, ceramic, or polymer matrix/binder.

While the quality, lifetime, wear-resistance and reliability of machining tools is of critical importance for many areas of industry, the perspectives of their improvement by simply choosing the binder (of very few options, like polymer, metal or ceramics) and changing cutting grains (from traditional carbides to superhard materials) have been practically exhausted even in previous century. However, noticing that the machining tools represent in fact composites, and that their cutting performance and wear resistance are controlled in the large degree by the binder [3], a new direction of the development of machining tools has been formulated, namely, hierarchical tools with nanoengineered binders [4, 5]. According to [4-7], nanoparticles introduced into the metallic binder of machining tools, increase the diamond grain/binder adhesion, enhance the binder strength and increase the reliability and wear resistance of the machining tools. Modification of metal binders with nanoparticles is an efficient method for enhancing their mechanical properties and, therefore, the operating parameters of tools [2,8]. Grains of various morphologies, physical and chemical properties can act as the reinforcing phase. Nanoparticles of refractory compounds, such as WC [9], $\mathrm{ZrO}_{2}$ [9, 19], $\mathrm{Al}_{2} \mathrm{O}_{3}$ [9], $\mathrm{Si}_{3} \mathrm{~N}_{4}$ [9], and $\mathrm{NbC}$ [10], are used most often for this purpose. It was found in $[6,7]$ that they can be arranged both along the boundaries and in the grain bulk of a binder. As a result, the binder is reinforced via the Orowan mechanism (slowing down the dislocation movement by dispersed particles) and due to inhibition of recrystallization. Dry lubricant powders, the compounds crystallizing in the hexagonal crystal system (e.g., boron nitride $\mathrm{hBN}$ ), are another type of nanomodifiers [20]. This additive significantly enhances strength and wear resistance of a binder. Another type of modifiers is the nanoparticles of various carbon allotropes such as fullerenes, nanodiamonds, and carbon nanotubes [4]. Identically to nanoparticles of refractory compounds, these additives impede binder grain growth during sintering or hot pressing. The positive effect of introducing these additives to the metal binders of various compositions has been proved for tools based on ultrahard materials that are used to machine a wide range of materials such as steels, granites, and concretes. Different nanoreinforcements (carbon nanotubes, boron nitride hBN, nanoparticles of tungsten carbide/WC) show different effects [6-11]. 
In recent studies of the effect of nanoreinforcements on composites, it was observed and proven theoretically that hybrid nanoscale reinforcements ensure better enhancement of the material properties as compared to single type nanoreinforcements [12-16]. Among the results, one can mention the synergy effects of nanodiamond with carbon nanotubes (CNT) and graphene, with enhancement of hardness and elastic modulus by $20 \ldots 25 \%$ [12], better dispersion of graphene particles with CNTs grown on them, leading to $40 \%$ and $46 \%$ increase in tensile modulus and strain [13]; better filler dispersion with no CNT rich-domains, intercalated graphene nanoplatelets (GNP) and CNT particles forming the 3D filler network in epoxy composites with various proportions of CNT/GNP reinforcements [14]; interconnected 3D network of nanofiller in composites and $10 \%$ higher flexural modulus than pure CNTs or GNPs in hybrid composites with a 9:1 CNT-GNP ratio [15] and so on.

In this work, we seek to explore the potential of the improvement of the diamond tools by using combined, hybrid nanoreinforcements in metallic binders. Various nanoparticles (WC, hBN and carbon nanotubes) and their combinations are introduced in the binder, and the resulting metallic nanocomposite binder and machining tools were tested. 3D hierarchical computational finite element model of the tool binder with hybrid nanoscale reinforcements is developed.

\section{Nanoengineered binder in diamond tools: Manufacturing and testing}

\subsection{Requirements to the binder of machining tools}

Machining tool binder has several important functions in the tool operation, including retaining the ultra-hard material grains in the working layer, ensuring gradual exposure of fresh cutting surfaces, heat transfer, etc. Cutting of materials such as concrete and sandstone is accompanied by formation of a large amount of abrasive slurry [17] that erodes the binder; as a result, diamonds that have not been worn down completely may be shed away from the working layer of the tool. Hence, choosing the optimal binder type and composition plays a significant role in designing cutting tools.

\section{$2.2 \quad$ Sample manufacturing}

The Fe-Ni-Mo composition (binder M) was selected as a basic binder in this study [18]. Carbonyl iron (average grain size of $7 \mu \mathrm{m}, 99.7 \mathrm{wt}$. \% purity), nickel (average grain size of $5 \mu \mathrm{m}, 99.94 \mathrm{wt}$. $\%$ purity), and molybdenum powders (average grain size of $5 \mu \mathrm{m}, 99.5 \mathrm{wt}$ \% purity) were used as 
starting materials for the binder. The tungsten carbide/WC nanoparticles used in this study were synthesized by the plasmochemical method. They were $80 \mathrm{~nm}$ in average size and contained up to $5 \%$ of impurities. The average grain size of the initial hBN powder was $10 \mu \mathrm{m}$; purity, $98 \%$.

According to [4] and [20], adding $0.1 \% \mathrm{hBN}, \mathrm{CNT}$ increases strength and hardness of metal matrix composite. Combined modification of binder material with carbon nanotubes and hBN particles has not been studied previously. In order to verify whether they are interchangeable or complement each other in the material, we investigated properties of the hot-pressed samples containing $0.1 \%$ of each additive and $0.05 \%$ of each additive $(0.1 \%$ in total $)$.

The content of WC nanoparticles was varied within the range of 0.69-2.76 wt. \%, which corresponds to $0.5-2$ vol. \%. Powder mixtures and compacted samples with WC nanoparticles were prepared with the optimized content of carbon nanotubes and hBN [20,4].

Binder components were mixed in a planetary ball mill (Fritsch, Germany) at a 15:1 weight ratio of the grinding bodies to the powder, rotational speed of $400 \mathrm{rpm}$, centrifugal factor of $22 \mathrm{~g}$, and mixing duration of $15 \mathrm{~min}$. In previous papers it was found [20,4] that milling the initial mixture in a planetary ball mill allows attaining uniform distribution of hBN and CNT nanoparticles.

The samples were compacted by hot pressing on a Dr. Fritsch DSP-475 setup in inert atmosphere at $950{ }^{\circ} \mathrm{C}, 350 \mathrm{MPa}$, and isobaric exposure for $3 \mathrm{~min}$. The samples prepared using this technology were $55 \times 10 \times 3 \mathrm{~mm}$ in size.

\subsection{Mechanical testing}

In order to study the bulk strength characteristics of the modified binders the ultimate tensile strength was determined on a Zwick Z250 universal testing machine (Germany) equipped with a sensor detecting the relative elongation. Samples were stretched at a rate of $4 \mathrm{~mm} / \mathrm{min}$. For these tests, we prepared three $55 \mathrm{~mm}$ long samples of each composition with the $4 \times 2.5 \mathrm{~mm}$ rectangular cross section by electric discharge sawing. Bending strength was determined by testing on a LF100 servo-hydraulic multipurpose testing machine (Walter + bai) with an external digital controller (EDC) using the three-point bending scheme. The Rockwell hardness was measured on a Wolpert 600 MRD Rockwell hardness tester. The residual porosity of the hot-pressed samples was determined by hydrostatic weighing on an analytical balance (A\&D, Japan) with an accuracy of $10^{-4} \mathrm{~g}$.

The mechanical properties (hardness and Young's modulus) of individual structural components of the hot-pressed samples were determined according to the results of matrix nanoindentation tests on a high-precision nanohardness tester (CSM Instruments) using the Oliver and Pharr 
method [21]. A diamond three-sided pyramid (Berkovich tip) was used as an indenter. The indentation load was $8 \mathrm{mN}$; the loading speed, $0.36 \mathrm{mN} / \mathrm{s}$; exposure to the maximum load, $5 \mathrm{~s}$. Indentation was performed at a step of $20 \mu \mathrm{m}$ along the $\mathrm{X}$ axis and $15 \mu \mathrm{m}$ along the $\mathrm{Y}$ axis. This indentation step was selected so that to make the indents on different structural components. The total number of indentation sites in the matrix was 100 .

\section{Structures and properties of metallic hybrid nanocomposites}

\subsection{Microstructure of metallic hybrid nanocomposites}

The phase composition of the hot-pressed samples was determined by X-ray diffraction analysis (XRD) on a DRON 4-07 automated X-ray diffractometer using monochromatic Co-K $\alpha$ radiation in the Bregg-Brentano geometry. Radiation was monochromatized using a graphite monochromator.

The structures of fractures and the polished surfaces of binders were studied by scanning electron microscopy on a Hitachi S-3400 N microscope equipped with a NORAN X-ray energy-dispersive spectrometer.

Fig. 1 shows the image of the structure of the hot-pressed sample of binder $\mathrm{M}$ featuring the two distinctive structural components: the matrix based on iron and nickel (dark gray regions) with the uniformly distributed grains of the molybdenum-containing phase (light regions) of elongated shape. The grains took this shape when powder mixtures were processed in planetary ball mills as a result of deformation caused by collisions with the grinding media and remained after hot pressing.

Studies of the phase composition by XRD analysis showed that the matrix consists of two phases and includes grains of phases of solid solution based on iron $(\alpha-\mathrm{Fe})$ (bcc lattice) and intermetallide $\mathrm{Fe}_{(1-\mathrm{x})} \mathrm{Ni}_{(\mathrm{x})}$ (fcc lattice) (Table 1). Local analysis of chemical composition by energy dispersive $\mathrm{X}$ ray spectroscopy and mapping (Fig. 2) showed that these phases are close to one another in terms of their chemical composition. Molybdenum mostly exists as the $\mathrm{Mo}_{3} \mathrm{Fe}_{3} \mathrm{O}$ phase that resulted from mutual diffusion of the components upon hot pressing. Only the central regions of the largest (>1 $\mathrm{mm}$ ) molybdenum grains don't contain iron, which is supported by elemental distribution maps (Fig. 2). 


\subsection{Effect of nanoparticles on the structure of the metallic bond}

To study the effect of nanoparticles on the structure, we investigated the fracture images of the samples of the initial binder M and nanoparticle-modified binder M (Fig. 3). The grain size was determined using the random linear intercept method according to the National State Standard GOST 5639-82 using the ImageScope image processing program. The aspect ratios of the $\mathrm{Mo}_{3} \mathrm{Fe}_{3} \mathrm{O}$ phase and matrix grains were also calculated. The measurement results are summarized in Table 2. Introduction of hBN nanoparticles and carbon nanotubes into the binder results in a 1.5 -fold decrease in the grain size of the matrix. The greatest effect is achieved by combined modification of the binder with all types of additives. Hence, the enhancement of mechanical properties upon modification of the binder with $\mathrm{hBN}$ nanoparticles and carbon nanotubes is associated with inhibition of recrystallization during hot pressing and, therefore, reduction of the grain size of alpha-Fe and $\mathrm{Fe}_{(1-\mathrm{x})} \mathrm{Ni}_{(\mathrm{x})}$ phases (Hall-Petch strengthening [22]).

\subsection{Morphology, location and distribution of hybrid nanoparticles.}

As noted in the previous section, the distribution and location of nanoparticles is one of the important factors controlling the effect of the hybrid nanoreinforcements.

In order to analyze the morphology, location and distribution of nanoparticles we have produced hot-pressed model samples with chemical composition $[80 \% \mathrm{Cu}-20 \% \mathrm{Ni}]-0.1 \% \mathrm{hBN}$ $+0.1 \% \mathrm{MWCNT}+0.69 \% \mathrm{WC}$. A thin foil was prepared from this sample and investigated by means of transmission electron microscopy using JEM 2100 microscope (JEOL, Japan). The composition of the matrix was chosen on the assumption that it doesn't demonstrate magnetic behaviour and thus no astigmatism correction is required during investigation. The procedure of powder mixture preparation and hot pressing was the same as described in paragraph $2.2-2.3$.

The distribution of hBN nanoplatelets in compact samples has an organized character (Fig. 4a). They can be found primarily at a perpendicular plane to the pressure direction and parallel to each. The length of nanopletelets may vary in the range $50-300 \mathrm{~nm}$ and their width $-20-50 \mathrm{~nm}$ (Fig. 4b). Carbon nanotubes are randomly oriented in the material and they are generally located inside of metal matrix grains (Fig. 4c). Their average length is $80 \mathrm{~nm}$.

WC particles can be moved inside grains of matrix [11] (based on $\alpha$-Fe and $\mathrm{Fe}_{(1-\mathrm{x})} \mathrm{Ni}_{(\mathrm{x})}$ phases) as a result of the shock impact of the grinding media during milling in the planetary ball mill or as a result of aggregation during recrystallization of two and more matrix grains with these nanoparticles residing on their boundaries. In this case we observed the same arrangement of WC 
particles (Fig. 4d). And occasionally they can be found on the grain boundaries «matrix-hBN». Nanoparticles of WC have a faceted shape and the average distance between WC nanoparticles is $400 \mathrm{~nm}$. These observations are taken into account in the computational models of the next section.

\subsection{Mechanical properties of metallic binder and nanoreinforcements}

The complex investigations of binder mechanical properties were carried out according the methods, described in 2.3 .

The binder $\mathrm{M}$ modified with $0.1 \% \mathrm{CNT}$ and $\mathrm{hBN}$ was found to be stronger than the $\mathrm{M}+0.1 \% \mathrm{hBN}$ and $\mathrm{M}+0.1 \% \mathrm{CNT}$ alloys by 100 and $40 \mathrm{MPa}$, respectively (Table 3). Hence, the effects of introducing these additives are combined.

The composition $\mathrm{M}+0.1 \% \mathrm{hBN}+0.1 \% \mathrm{CNT}$ with the optimal physical and mechanical properties was additionally modified with various concentrations of WC nanoparticles. The best properties were achieved in the composition containing $0.69 \%$ of WC. The increased WC content reduced strength and hardness of the hot-pressed samples, primarily by rising their residual porosity.

In order to compare stress-strain behavior of pure matrix $M$ with nanoparticle containing composites, a set of tensile tests was carried out. The samples of pure binder M demonstrated the lowest average tensile strength $718 \mathrm{MPa}$ (Table 4). The separate introduction of nanoparticles hBN and CNT leads to of strength up to $900 \mathrm{MPa}$. In the case of combined introduction of these nanoparticles we observed additional strength improving. The samples with hybrid nanomodification showed the best mechanical properties. Moreover, binders modified with nanoparticles had a tendency to enhancing of ductile properties (Fig. 5). It can be seen from higher tensile extension.

Mechanical properties of individual structural components of the hot-pressed samples of binder M were determined using nanoindentation tests (Table 5). The average indent size was $0.8 \mu \mathrm{m}$, which is larger than the average grain size of the $\alpha-F e$ and $\mathrm{Fe}_{(1-\mathrm{x})} \mathrm{Ni}_{(\mathrm{x})}$ phases. For this reason, as well as because the chemical composition and mechanical properties of these phases are similar, $\alpha-\mathrm{Fe}$ and $\mathrm{Fe}(1-\mathrm{x}) \mathrm{Ni}(\mathrm{x})$ phases were considered as one structural component. The $\mathrm{Mo}_{3} \mathrm{Fe}_{3} \mathrm{O}$ phase was identified because its hardness and the Young's modulus significantly stood out. The subsequently recorded SEM images also proved that the indenter penetrated into the $\mathrm{Mo}_{3} \mathrm{Fe}_{3} \mathrm{O}$ grains in this case. 
Figure 6 shows the typical load-displacement curves. The average depth of indenter penetration into grains of the $\alpha-\mathrm{Fe}$ and $\mathrm{Fe}_{(1-\mathrm{x})} \mathrm{Ni}_{(\mathrm{x})}$ phase is $\sim 280 \mu \mathrm{m}$ for the initial binder and $230 \mu \mathrm{m}$ for all the samples of the modified compositions, being indicative that hardness has increased. Hardness of the $\alpha-\mathrm{Fe}$ and $\mathrm{Fe}_{(1-\mathrm{x})} \mathrm{Ni}_{(\mathrm{x})}$ phases in the modified binders varies within the range of 5.5-6.5 GPa, which is higher than that of the initial nanoparticles free binder by $40-60 \%$.

\subsection{Wear resistance of new materials}

In order to investigate wear resistance of binder M and the effect of hBN, CNT, and WC nanoparticles, a series of tribological studies involving sliding tests were performed. The samples were subjected to tribological tests on an automated tribometer (CSM Instruments) using rotational motion in the pin-on-disk regime under the following conditions: wear track radius, $6.8 \mathrm{~mm}$; the load applied, $2 \mathrm{~N}$; the maximum speed, $10 \mathrm{~cm} / \mathrm{s}$; a ball $3 \mathrm{~mm}$ in diameter made of sintered aluminum oxide $\left(\mathrm{Al}_{2} \mathrm{O}_{3}\right)$ used as a counter body; travel length, $214 \mathrm{~m}$ (5,000 cycles), air used as the medium. Specific wear of the samples was calculated using the profile diagram and 3D images of wear tracks recorded on a VEECO WYKO NT1100 optic profilometer after the tests. A sintered $\mathrm{Al}_{2} \mathrm{O}_{3}$ ball was used as a counterbody. Using this counter body allows one to simulate the actual operating conditions for the tool and assess the behavior of the binder subjected to abrasion when contacting a harder material with higher wear resistance (concrete being used in actual conditions).

The results of the tests (specific wear of binders) are summarized in Figure 7. Figure 8 shows 3D images of wear track fragments after tribological tests for the samples of various binders (here, for pure metal binder, and the binder with $0.1 \% \mathrm{hBN}+0.1 \% \mathrm{CNT}+0.69 \% \mathrm{WC})$.

The results of tribological tests showed that the initial binder $M$ is characterized by the lowest wear resistance. Introduction of modifying nanoparticles enhances the wear resistance of binder. The specific wear of the binder samples is reduced drastically as a result of nanoreinforcements: by $83 \% \ldots 100 \%$ if the binder is modified by $\mathrm{hBN}$ or only CNT or their combination, and by 3.5 times if the binder is modified by all the three types of nanoparticles in combination.

\section{Modelling hybrid metallic nanocomposites}

\subsection{Hierarchical computational finite element model of nanoengineered binder}

Here, we seek to simulate the deformation and mechanical behaviour of nanoreinforced metallic composites. Let us estimate the geometrical feature of a representative unit cells. The length of carbon nanotubes was taken $80 \mathrm{~nm}$, the diameter $4 \mathrm{~nm}$. The hBN particles were taken as discs, 
with diameter $150 \mathrm{~nm}$ and thickness $30 \mathrm{~nm}$. The WC particles were taken also as discs, with thickness and diameter $80 \mathrm{~nm}$. For this case, a unit cell with the linear size $1000 \mathrm{~nm}$ contains 754 carbon nanotubes, $3 \mathrm{hBN}$ particles and 17 tungsten carbide particles.

In order to simulate such a material, a model should be divided into two scales [25, 28]: (a) low level model: metallic matrix reinforced by $\sim 10^{3} \mathrm{CNT}$ particles $[28,29]$, and (b) high level model: unit cell with several... up to dozens $\mathrm{hBN}$ and $\mathrm{WC}$ nanoparticles, and matrix which properties have been obtained from the lower level model. The two-scale unit cell was developed. A schema of such a two level model is shown in Figure 9.

For the efficient computational testing of various structures, a new computational code for the automatic generation of 3D unit cell models of nanocomposites was developed [27, 29, 30]. The program, written in Compaq Visual Fortran, generates a Python code, which is run in the finite element software Abaqus and generates FE models with pre-defined parameters.

The program here allows the generation of both disc-shaped, cylinder-shaped and snake-shaped particles. The coordinates of initial point of each NC particle was given by three random numbers inside the cell, determined using the random number generator. Random Sequential Adsorption approach/RSA for the snake-shaped inclusions is realized. This approach consists in a sequential addition of randomly oriented reinforcements to a unit cell, ensuring that the particles do not overlap [25, 26-29].The distances between newly generated points and all the available points were checked, and if the points were at the same place, too close or out of box, the point was generated anew (RSA algorithm). The meshing of the complex unit cell is carried out using the embedding element meshing approach (EEM), where the structures with very fine meshes are embedded into regular meshes of the unit cell. Figure 10 shows examples of the unit cells.

\subsection{Deformation behaviour of hybrid nanocomposites and contribution of different nanoparticles}

Using the developed computational models, we carried out the numerical testing of metallic nanocomposites for the following cases: binder reinforced with $0.1 \% \mathrm{CNT}$, with $0.1 \% \mathrm{CNT}+$ $0.1 \% \mathrm{hBN}$ and with $0.1 \% \mathrm{CNT}+0.1 \% \mathrm{hBN}+0.69 \% \mathrm{WC}$. The Young modulus of $\mathrm{hBN}$ platelets is taken as $675 \mathrm{GPa}$ [5], and of CNT is $1 \mathrm{TPa}$ [4]. The modulus of elasticity of WC is $600 \mathrm{GPa}$. The Young modulus of the metallic binder was taken $170 \mathrm{MPa}$. The stress-strain curve of the metallic binder was taken from the data on Figure 5.

In order to analyze the effect of nanoscale reinforcement on the mechanical properties and damage behavior of the binder, a number of 3D unit cells was generated, and tested. The unit cell size was 
300x300x300 nm (for lower model) and 1100x1100x1100 nm (for upper model). Each unit cell was subject to tensile loading, displacement $2 \%$. Figure 11 shows the stress and displacement distribution in the carbon nanotube particles. It can be seen that the stress are rather high at the CNT particles. However, the stress strain curve of the binder with CNT is very close to the curve of pure binder, apparently, due to the very low content of nanotubes. Further, according to other investigations, nanoparticles are expected to influence the compressive, interface modulus and adhesion properties, and not tensile behavior [27-29]. Comparing this observation (negligible strengthening effect of CNT particles on the metallic binder) with the data from Table 2 (reduced grain sizes) and results of studies in [4], one can conclude, again, that the effect of carbon nanotubes lies not in the direct mechanical strengthening, but rather in changed properties of metallic materials, with reduced grain size and increased strength as a result.

Further, the stress-strain curves for the pure binder (without CNT reinforcement, large grains) and CNT-modified binder were introduced into the higher scale models, one with only hBN particles (4 particles) and one with mixed hBN and WC nanoparticles. Figure 12 shows the stress concentration in the matrix cut of the unit cell with hBN particles. The stiffness of the material increases by $4 \ldots 5 \%$ if the binder is reinforced by $\mathrm{hBN}$ and by $6 \ldots 7 \%$ if the binder is reinforced by both $\mathrm{hBN}$ and WC (additionally to the $20 \%$ effect of CNT due to the grain size reduction [4]). However, given the combined effect of CNT reinforcement (reducing the grain size, and thus, stiffening the matrix) and mechanical reinforcement by $\mathrm{hBN}$ and WC, this effect becomes stronger.

It is of interest to compare this observation with the studies of wear resistance presented in the section 3.5. We assume that the wear is controlled by kind of nanoscale cutting out/detachment processes at the surface of the binder. Applying the model of the material removal rate from [4], one can estimate that the wear rate should be reduced by $7 \ldots 8 \%$ due to the nanoreinforcements.

However, the experiments shown in section 3.5 demonstrate much bigger wear rate reduction. In order to evaluate the effect of these nanoreinforcements correctly, one should separate their physical effects. While CNT plays role as a modifier of the binder (it reduces the grain size and thus increases the stiffness and strength, leading to $20 \%$ higher flow stress [4]) and purely mechanical role of WC particles (increasing the stiffness or flow stress according roughly to the rule of mixture), the hBN particles play a role of not only of mechanical reinforcing (as in the case of tensile loading above), but also a role of solid lubricant [5], increasing the contact angles, thus, increasing the hydrophobic nature of the material [31]. Additions of small amount of hBN can lead to up to $50 \% \ldots 800 \%$ reduced wear resistance depending on the humidity [31].

In order to estimate the possible effect of $\mathrm{hBN}$ as a lubricant quanttatively, let us use the following simplified model. A counterbody/indenter with the width B moving over the distance $\mathrm{L}$ goes over $\mathrm{N}_{1}$ 


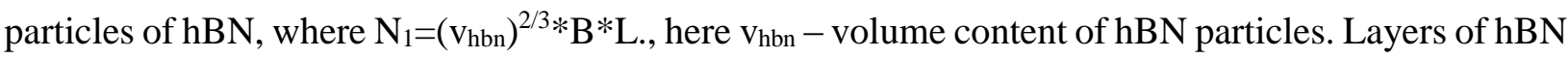
can bet hen attached to the indenter, playing role of a lubricant, and drastically reducing the friction and wear. We assume that the lubricant nanovolumes are only attached to the areas which touched the $\mathrm{hBN}$ particles. Thus, $\left(\mathrm{V}_{\mathrm{hbn}}\right)^{1 / 3}$ section of the indenter (along the width $\mathrm{B}$ ) is covered by lubricant, while the rest has the same friction coefficient. For the given volume content of hBN $0.69 \%$, it coresponds to $19 \%$ of the indenter/conterbody covered in lubricant. Apparently, it can reduce the wear drastically - not by $0.5 \ldots 1 \%$ (as in the case of mechanical properties), but up to $19 \%$. This (oversimplified) model shows the potential of lubricating nanoparticles as reinforcement for the wear resistance of nanocomposites.

Thus, the strong positive effect of this combined nanoscale reinforcement is caused not by accumulation of mechanical effects, but rather by combination of different structure controlling effects, namely, grain size reducing effect of carbon nanotubes, mechanical reinforcement of tungsten carbine, and (specifically for the wear) lubricating properties of hBN particles.

It is of interest to compare the obtained results with the results obtained for the metallic binders with the single-type nanoparticle reinforcement [2, 5]. In [2], the metallic binders with single nanoscale reinforcement (carbon nanotubes, CNT) were studied. It was observed that the CNT modified metal binders lead to improvement of diamond tool performances, namely, 20\% higher flow stress and $60 \%$ higher plastic extension (at $0.1 \%$ MWCNT reinforcement) and cutting speed increased by $50 \ldots 70 \%$, while tool lifetime only slightly deviates from the usual values. You and Gao [32] developed CNT based grinding wheels, with CNTs used as cutting grains, and epoxy as binder. In [5], superhard cut-off wheels modified by hBN particles were studied, and $\mathrm{t}$ was proven that was $80 \%$ more efficient compared to the tool with the original binder, due to the strengthening and better diamond retention properties, leading to lesser binder wear. One can be seen that the effects on the hybrid nanoreinforcements observed in this work are much stronger than those of single reinforcements, also thanks to the synergic effects of various nanoparticles.

\section{Conclusions}

Hybrid metallic nanocomposites are demonstrated to have much better mechanical properties than both nanoparticles free metallic binder and nanocomposites reinforced with only one types of nanoparticles. Combining nanoreinforcements of different types and shapes (here, stiff and long carbon nanotubes, soft disc-shaped boron nitride $\mathrm{hBN}$, and equiaxial tungsten carbide/WC) in the same binder material, one can improve synergistically the mechanical properties, strength of the binder, and, ultimately, improve the wear resistance and reliability of machining tools. Introduction of hBN nanoparticles and carbon nanotubes into the binder results in a 1.5-fold decrease in the grain size of the matrix (if single particles) and by 1.73-fold (if hybrid particles). The strength of nanocomposites (with $0.1 \% \mathrm{hBN}$ or $0.1 \% \mathrm{WC}$ ) is $24 \ldots 26 \%$ higher 
than that of pure metallic matrix, and for the case pf hybrid nanoreinforcements, the strength is $33 \%$ higher (hBN plus CNT) up to $44 \%$ (all three types of particles). Further, the specific wear of the machining tools with these binders is reduced drastically as a result of nanoreinforcements: by $83 \% \ldots 100 \%$ if the binder is modified by hBN or only CNT or their combination, and by 3.5 times (!) if the binder is modified by all the three types of nanoparticles in combination. A multiscale computational model of the nanomodified binder with hybrid reinforcements is developed. Summarizing, one can conclude that the hybrid metallic materials reinforced by several various nanoparticles ensure much better mechanical properties and strength that the single reinforcement nanocomposites and, even more clearly, non-reinforced metallic matrices. If such materials are used in machining tools as binder, the wear resistance of the tools can be reduced by up to 3.5 times.

\section{Acknowledgements:}

The work was carried out with financial support from the Ministry of Education and Science of the Russian Federation in the framework of the Increase Competitiveness Program of National University of Science and Technology "MISiS" (project no.K2-2016-073) in the part of hybrid nanocomposites deformation behavior modelling and from the Russian Foundation for Basic Research and Moscow Government in the framework of project no. 15-38-70019 «mol_a_mos» in the part of studying the effect of nanoparticles on mechanical properties and wear resistance of binders. 


\section{References}

1. H. K. Tönshoff, B. Denkena, H.H. Apmann. Diamond Tools for Wire Sawing Metal Components // Key Engineering Materials. -2003. - Vol. 250. - P. 33-40.

2. D. Sidorenko, P. Loginov, E. Levashov, L. Mishnaevsky. Hierarchical machining materials and their performance // MRS Bulletin. - 2016. - Vol. 41. - P. 678-682.

3. L. L. Mischnaewskij, Verschleiss von Diamant- und CBN-Scheiben beim Schleifen zäher Metalle. Ind.Diam.Rdsch., 1993, t. 27, nr 1, s. 50-54.

4. D. Sidorenko, L. Mishnaevsky Jr., E. Levashov, P. Loginov, M. Petrzhik. Carbon nanotube reinforced metal binder for diamond cutting tools // Materials \& Design. - 2015. - Vol. 83. - P. 536-544.

5. P. Loginov, L. Mishnaevsky Jr. E. Levashov, M. Petrzhik, Diamond and CBN hybrid and nanomodified cutting tools with enhanced performances: Development, testing and modelling, Materials and Design, 88 (2015) 310-319

6. A. A. Zaitsev, D. A. Sidorenko, E. A. Levashov, V. V. Kurbatkina, V. A. Andreev, S. I. Rupasov, P. V. Sevast'yanov. Diamond Tools in Metal Bonds Dispersion-Strengthened with Nanosized Particles for Cutting Highly Reinforced Concrete // Journal of Superhard Materials. - 2010. - Vol. 32. - No. 6. - P. 423-431.

7. E. Levashov, V. Kurbatkina, A. Zaytsev. Improved Mechanical and Tribological Properties of MetalMatrix Composites Dispersion-Strengthened by Nanoparticles // Materials. - 2010. - Vol. 3. - P. 97109.

8. N.I. Polushin, M.S. Ovchinnikova, A.L. Maslov. The Use of Alumina Nanoparticles as Modifiers of Galvanic Binder of Diamond Tools // Advanced Materials Research. - 2014. - Vol. 1040. - P. 199201.

9. A. A. Zaitsev, V. V. Kurbatkina, E. A. Levashov. Features of the Influence of Nanodispersed Additions on the Process of and Properties of the Fe-Co-Cu-Sn Sintered Alloy // Russian Journal of Non-Ferrous Metals. - 2008. - Vol. 49. - No. 5. - P. 414-419.

10. Zaitsev A.A., Sidorenko D.A., Levashov E.A., Kurbatkina V.V., Rupasov S.I., Andreev V.A., Sevast'Yanov P.V. Development and application of the $\mathrm{Cu}-\mathrm{Ni}-\mathrm{Fe}-\mathrm{Sn}$-based dispersion-hardened bond for cutting tools of superhard materials // Superhard Materials. - 2012. - Vol. 34. - Iss. 4. - P. 270280.

11. E. Levashov, V. Kurbatkina, A. Zaytsev. Improved Mechanical and Tribological Properties of MetalMatrix Composites Dispersion-Strengthened by Nanoparticles // Materials. - 2010. - Vol. 3. - P. 97 109.

12. Prasad KE, Das B, Maitra U, Ramamurty U, Rao CNR. Extraordinary synergy in the mechanical properties of polymer matrix composites reinforced with 2 nanocarbons. PNAS 2009;106:13186-9. doi:10.1073/pnas.0905844106. 
13. Li W, Dichiara A, Bai J. Carbon nanotube-graphene nanoplatelet hybrids as high-performance multifunctional reinforcements in epoxy composites. Composites Science and Technology 2013;74:221-7. doi:10.1016/j.compscitech.2012.11.015.

14. Yue L, Pircheraghi G, Monemian SA, Manas-Zloczower I. Epoxy composites with carbon nanotubes and graphene nanoplatelets - Dispersion and synergy effects. Carbon 2014;78:268-78. doi:10.1016/j.carbon.2014.07.003.

15. Chatterjee S, Nafezarefi F, Tai NH, Schlagenhauf L, Nüesch FA, Chu BTT. Size and synergy effects of nanofiller hybrids including graphene nanoplatelets and carbon nanotubes in mechanical properties of epoxy composites. Carbon 2012;50:5380-6. doi:10.1016/j.carbon.2012.07.021.

16. A.Pontenfisso, L. Mishnaevsky Jr., Nanomorphology of graphene and CNT reinforced polymer and its effect on damage: Micromechanical numerical study, Composite B (2016), pp. 338-349

17. J. S. Konstanty, D. Tyrala. Wear mechanism of iron-base diamond-impregnated tool composites // Wear. - 2013. - Vol. 303. - Iss. 1-2. - P. 533-540.

18. H. C.P. de Oliveira, A. Coelho, P. M. Amaral, J. C. Fernandes, L. G. Rosa. Comparison between Cobalt and Niobium as a Matrix Component for Diamond Impregnated Tools Used for Stone Cutting // Key Engineering Materials. - 2013. - Vol. 548. - P. 98-105.

19. Sun Y., Wu H., Li M., Meng Q., Gao K., Lü X., Liu B. The effect of $\mathrm{ZrO}_{2}$ nanoparticles on the microstructure and properties of sintered WC-bronze-based diamond composites // Materials. - 2016. - Vol. 9. - Iss. 5. - Article number 343.

20. P.A. Loginov, E.A. Levashov, V.V. Kurbatkina, A.A. Zaitsev, D.A. Sidorenko. Evolution of the microstructure of $\mathrm{Cu}-\mathrm{Fe}-\mathrm{Co}-\mathrm{Ni}$ powder mixtures upon mechanical alloying // Powder Technology. 2015. - Vol. 276. - P. 166-174.

21. W.C. Oliver, G.M. Pharr. Improved technique for determining hardness and elastic modulus using load and displacement sensing indentation experiments // Journal of Materials Research. - 1992. Vol. 7. - Iss. 6. - P. 1564-1580.

22. M.A. Meyers, A. Mishra, D.J. Benson. Mechanical properties of nanocrystalline materials // Progress in Materials Science. - 2006. - Vol.51. - Iss. 4. - P. 427-556.

23. Yang S-Y, Lin W-N, Huang Y-L, Tien H-W, Wang J-Y, Ma C-CM, et al. Synergetic effects of graphene platelets and carbon nanotubes on the mechanical and thermal properties of epoxy composites. Carbon 2011;49:793-803. doi:10.1016/j.carbon.2010.10.014.

24. A. Kumar, K. V. Sharma, A. Gupta, J. Tywoniak, P. Hajek. Optimization of processing parameters of medium density fiberboard using response surface methodology for multiwalled carbon nanotubes as a nanofiller // European Journal of Wood and Wood Products. - 2017. - Vol. 75. - Iss. 2. - P. $203-$ 213.

25. L. Mishnaevsky Jr, Computational Mesomechanics of Composites, John Wiley, 2007, 280 pp.

26. G.M. Dai, L. Mishnaevsky Jr., Damage evolution in nanoclay-reinforced polymers: a threedimensional computational study, Composites Science \& Technology, 74 (2013) 67-77 
27. G.M. Dai, L. Mishnaevsky Jr., Graphene monolayer nanocomposites: 3D simulation of damage and fracture, Computational Materials Science, Vol. 95, 2014, pp. 684-692

28. G.M. Dai, L. Mishnaevsky Jr., Fatigue of multiscale composites with secondary nanoplatelet reinforcement: 3D computational analysis, Composites Science and Technology, Vol. 91, 2014, pp. 71-81

29. G.M. Dai, L. Mishnaevsky Jr , Carbone nanotube reinforced hybrid composites: computational modelling of environmental fatigue and usability for wind blades, Composites Part B (2015), pp. 349-360

30. A.Pontenfisso, L. Mishnaevsky Jr., Nanomorphology of graphene and CNT reinforced polymer and its effect on damage: Micromechanical numerical study, Composite B (2016), pp. 338-349

31. J. Chen et al, Enhancement of mechanical and wear resistance performance in hexagonal boron nitride-reinforced epoxy nanocomposites, Polymer International Volume 66, Issue 5, 659-664

32. J. You, Y. Gao A Study of Carbon Nanotubes as Cutting Grains for Nano Machining, 2009, Advanced Materials Research, 76-78, 502 
Table 1. The phase composition of the hot-pressed $\mathrm{M}$ binder

\begin{tabular}{|c|c|c|c|}
\hline Phase & Space group & Wt. fraction, \% & Lattice constant, $\AA$ \\
\hline alpha-Fe & cI2/1 & 64 & $\mathrm{~A}=2.878$ \\
\hline $\mathrm{Mo}_{3} \mathrm{Fe}_{3} \mathrm{O}$ & $\mathrm{cF} 112 / 2$ & 3 & $\mathrm{~A}=11.110$ \\
\hline $\mathrm{Fe}_{3} \mathrm{O}_{4}$ & $\mathrm{cF} 56 / 2$ & 2 & $\mathrm{~A}=8.511$ \\
\hline $\mathrm{Fe}_{(1-\mathrm{x})} \mathrm{Ni}_{(\mathrm{x})}$ & $\mathrm{cF} 4 / 1$ & 31 & $\mathrm{~A}=3.589$ \\
\hline
\end{tabular}


Table 2. The average grain size of $\alpha-\mathrm{Fe}, \mathrm{Fe}_{(1-\mathrm{x})} \mathrm{Ni}_{(\mathrm{x})}$ and $\mathrm{Mo}_{3} \mathrm{Fe}_{3} \mathrm{O}$ phases in the hot-pressed M binders

\begin{tabular}{|c|c|c|c|}
\hline & \multicolumn{3}{|c|}{ Grains of the $\alpha-\mathrm{Fe}$ and $\mathrm{Fe}_{(1-\mathrm{x})} \mathrm{Ni}_{(\mathrm{x})}$ phases } \\
\hline Composition & Length, $\mu \mathrm{m}$ & Width, $\mu \mathrm{m}$ & Aspect ratio \\
\hline $\mathrm{M}$ & 0.64 & 0.45 & 1.42 \\
\hline $\mathrm{M}+0.1 \% \mathrm{hBN}$ & 0.42 & 0.3 & 1.4 \\
\hline $\mathrm{M}+0.1 \% \mathrm{CNT}$ & 0.43 & 0.3 & 1.43 \\
\hline $\mathrm{M}+0.05 \% \mathrm{hBN} 0.05 \% \mathrm{CNT}$ & 0.37 & 0.27 & 1.37 \\
\hline $\mathrm{M}+0.1 \% \mathrm{hBN}+0.1 \% \mathrm{CNT}$ & 0.34 & 0.26 & 1.31 \\
\hline \multirow[t]{2}{*}{$\mathrm{M}+0.1 \% \mathrm{hBN}+0.1 \% \mathrm{CNT}+0.69 \% \mathrm{WC}$} & 0.39 & 0.26 & 1.5 \\
\hline & \multicolumn{3}{|c|}{ Grains of the $\mathrm{Mo}_{3} \mathrm{Fe}_{3} \mathrm{O}$ phase } \\
\hline Composition & Length, $\mu \mathrm{m}$ & Width, $\mu \mathrm{m}$ & Aspect ratio \\
\hline M & 2.84 & 0.52 & 5.46 \\
\hline $\mathrm{M}+0.1 \% \mathrm{hBN}$ & 3.44 & 0.45 & 7.64 \\
\hline $\mathrm{M}+0.1 \% \mathrm{CNT}$ & 3.05 & 0.44 & 6.93 \\
\hline $\mathrm{M}+0.05 \% \mathrm{hBN} 0.05 \% \mathrm{CNT}$ & 3.68 & 0.45 & 8.18 \\
\hline $\mathrm{M}+0.1 \% \mathrm{hBN}+0.1 \% \mathrm{CNT}$ & 4.66 & 0.46 & 10.13 \\
\hline $\mathrm{M}+0.1 \% \mathrm{hBN}+0.1 \% \mathrm{CNT}+0.69 \% \mathrm{WC}$ & 3.54 & 0.37 & 9.57 \\
\hline
\end{tabular}


Table 3. Physical and mechanical properties of the nanomodified $M$ binders

\begin{tabular}{|l|l|l|l|}
\hline Composition & $\phi, \%$ & Hardness, HRB & $\begin{array}{l}\text { Ultimate bending } \\
\text { strength, MPa }\end{array}$ \\
\hline $\mathrm{M}$ & & $110 \pm 1$ & $1588 \pm 50$ \\
\hline $\mathrm{M}+0.1 \% \mathrm{hBN}$ & & $110 \pm 1$ & $1703 \pm 25$ \\
\hline $\mathrm{M}+0.1 \% \mathrm{MWCNT}$ & $109 \pm 1$ & $1763 \pm 10$ \\
\hline $\mathrm{M}+0.05 \% \mathrm{hBN} 0.05 \% \mathrm{MWCNT}$ & $109 \pm 1$ & $1620 \pm 60$ \\
\hline $\mathrm{M}+0.1 \% \mathrm{hBN}+0.1 \% \mathrm{MWCNT}$ & $110 \pm 1$ & $1800 \pm 65$ \\
\hline $\mathrm{M}+0.1 \% \mathrm{hBN}+0.1 \% \mathrm{MWCNT}+0.69 \% \mathrm{WC}$ & & $110 \pm 2$ & $1845 \pm 10$ \\
\hline $\mathrm{M}+0.1 \% \mathrm{hBN}+0.1 \% \mathrm{MWCNT}+1.38 \% \mathrm{WC}$ & & $108 \pm 1$ & $1780 \pm 10$ \\
\hline $\mathrm{M}+0.1 \% \mathrm{hBN}+0.1 \% \mathrm{MWCNT}+2.76 \% \mathrm{WC}$ & & $108 \pm 1$ & $1364 \pm 30$ \\
\hline
\end{tabular}


Table 4. Mechanical properties of hot-pressed M binders

\begin{tabular}{|l|c|c|c|}
\hline \multicolumn{1}{|c|}{ Composition } & $\mathrm{R}_{\mathrm{m}}, \mathrm{MPa}$ & $\mathrm{E}, \mathrm{GPa}$ & $\Delta, \%$ \\
\hline $\mathrm{M}$ & 718 & 166 & 0.3 \\
\hline $\mathrm{M}+0.1 \% \mathrm{hBN}$ & 886 & 169 & 1.2 \\
\hline $\mathrm{M}+0.1 \% \mathrm{MWCNT}$ & 909 & 176 & 1.1 \\
\hline $\mathrm{M}+0.05 \% \mathrm{hBN} 0.05 \% \mathrm{MWCNT}$ & 954 & 170 & 1.4 \\
\hline $\mathrm{M}+0.1 \% \mathrm{hBN}+0.1 \% \mathrm{MWCNT}$ & 954 & 186 & 1.5 \\
\hline $\mathrm{M}+0.1 \% \mathrm{hBN}+0.1 \% \mathrm{MWCNT}+0.69 \% \mathrm{WC}$ & 1031 & 175 & 1.4 \\
\hline
\end{tabular}


Table 5. Properties of the individual structural components of the hot-pressed $\mathrm{M}$ binders measured by matrix nanoindentation

\begin{tabular}{|l|l|l|l|l|l|l|}
\hline \multirow{2}{*}{ Composition } & \multicolumn{4}{l}{$\alpha-\mathrm{Fe}$ and $\mathrm{Fe}_{(1-\mathrm{x})} \mathrm{Ni}_{(\mathrm{x})}$ phases } & \multicolumn{2}{l|}{$\mathrm{Mo}_{3} \mathrm{Fe}_{3} \mathrm{O}$ phase } \\
\cline { 2 - 7 } & $\mathrm{H}, \mathrm{GPa}$ & $\mathrm{E}, \mathrm{GPa}$ & $\mathrm{R}, \%$ & $\mathrm{H}, \mathrm{GPa}$ & $\mathrm{E}, \mathrm{GPa}$ & $\mathrm{R}, \%$ \\
\hline $\mathrm{M}$ & $4.0 \pm 0.3$ & $191 \pm 6$ & 13.87 & $10.4 \pm 1.0$ & $245 \pm 21$ & 47.32 \\
\hline $\mathrm{M}+0.1 \% \mathrm{hBN}$ & $5.5 \pm 0.9$ & $207 \pm 13$ & 18.32 & $10.8 \pm 1.2$ & $236 \pm 15$ & 49.15 \\
\hline $\mathrm{M}+0.1 \% \mathrm{CNT}$ & $6.5 \pm 0.7$ & $214 \pm 10$ & 17.90 & $10.9 \pm 1.1$ & $248 \pm 20$ & 49.66 \\
\hline $\mathrm{M}+0.05 \% \mathrm{hBN} 0.05 \% \mathrm{CNT}$ & $5.8 \pm 0.7$ & $216 \pm 12$ & 20.96 & $11.4 \pm 1.2$ & $244 \pm 12$ & 50.05 \\
\hline $\mathrm{M}+0.1 \% \mathrm{hBN}+0.1 \% \mathrm{CNT}$ & $6.2 \pm 0.9$ & $214 \pm 13$ & 18.88 & $11.1 \pm 1.8$ & $236 \pm 24$ & 48.72 \\
\hline $\begin{array}{l}\mathrm{M}+0.1 \% \mathrm{hBN} \\
+0.1 \% \mathrm{CNT}+0.69 \% \mathrm{WC}\end{array}$ & $5.6 \pm 1.1$ & $213 \pm 16$ & 20.57 & $12.3 \pm 1.5$ & $240 \pm 18$ & 51.85 \\
\hline
\end{tabular}




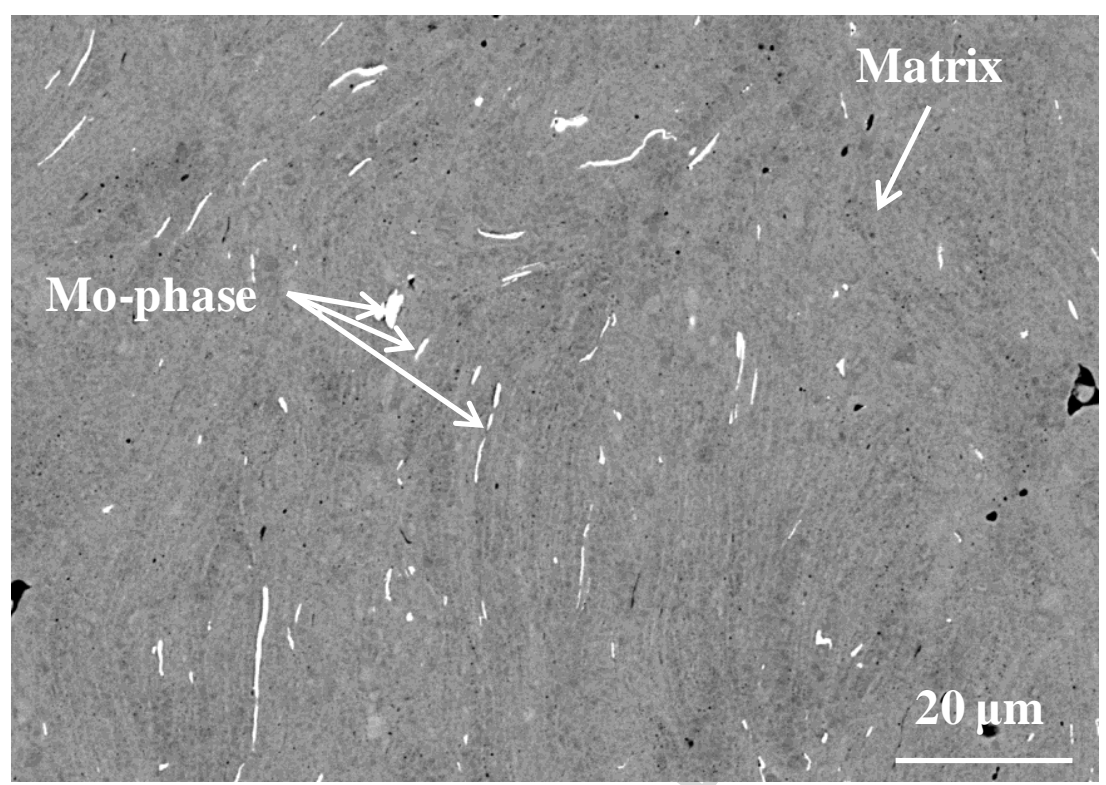

Fig. 1. The structure of the hot-pressed $\mathrm{M}$ binder

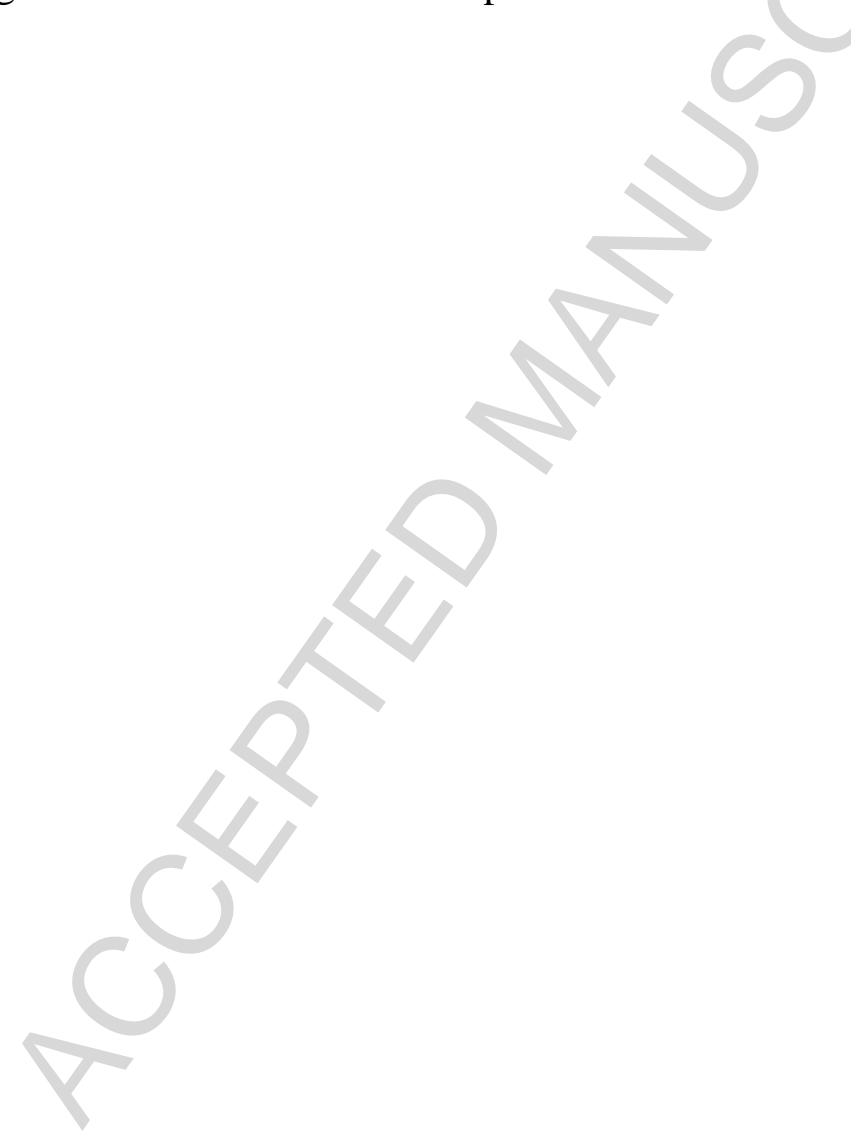




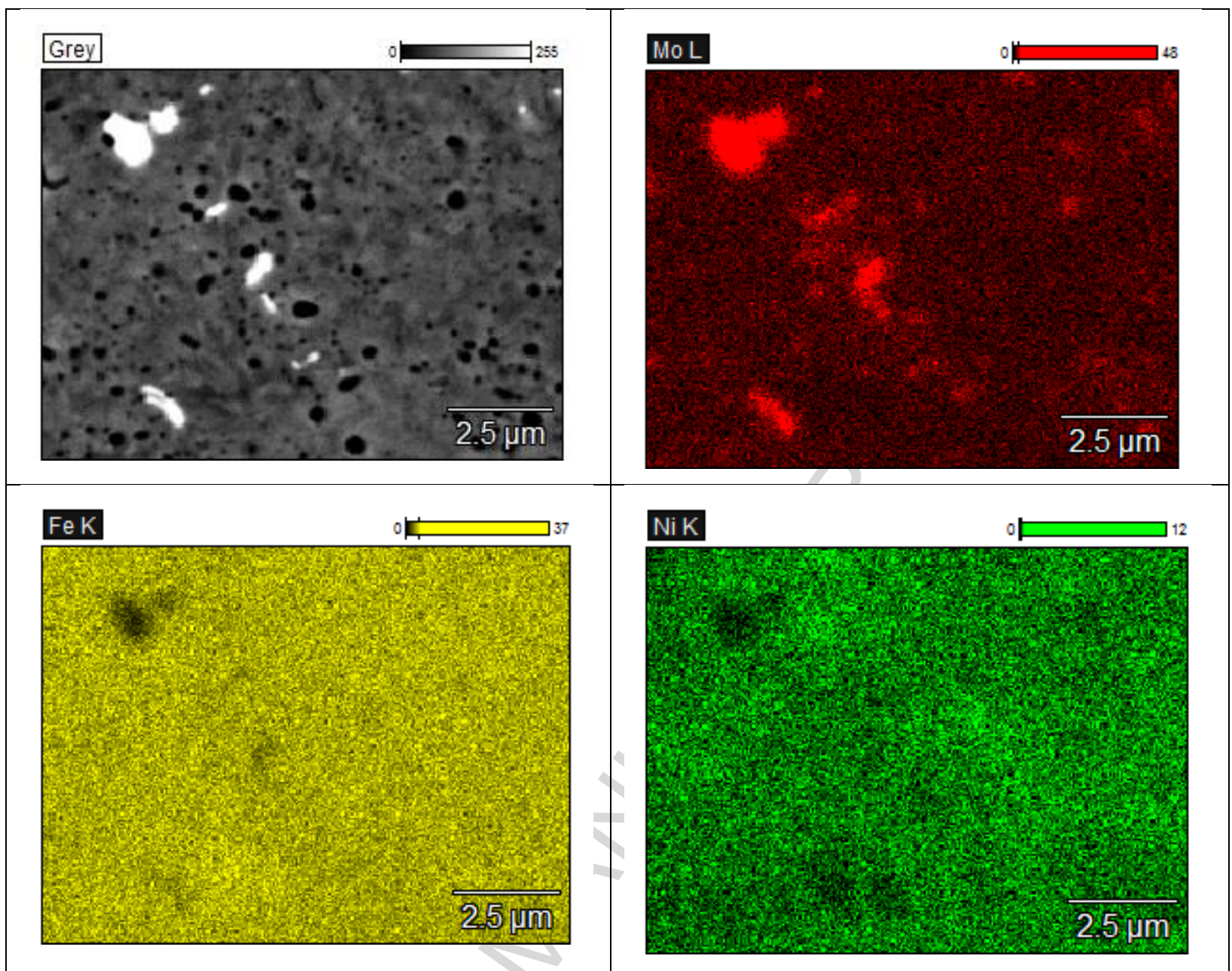

Fig. 2. EDX elemental mapping of hot pressed M binder 


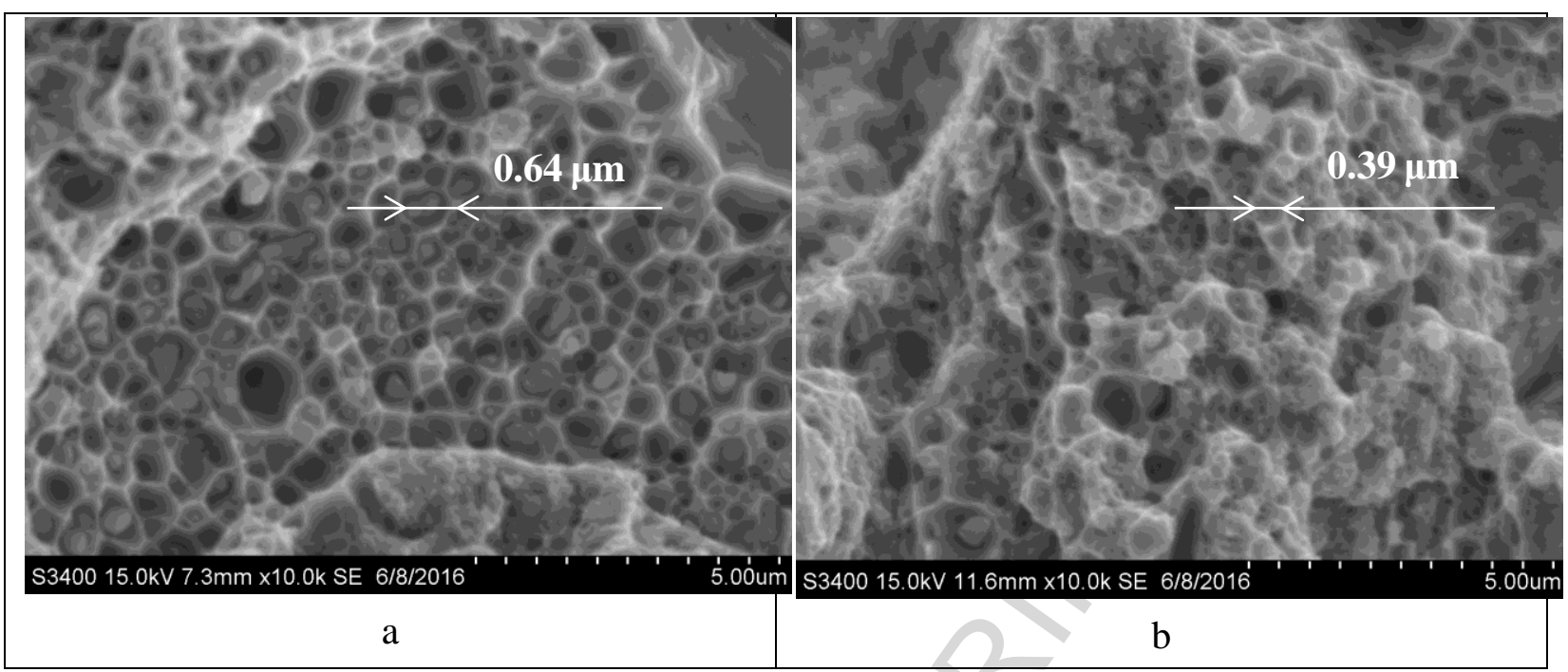

Fig. 3. The failure patterns of binders $\mathrm{M}$ (a) and $\mathrm{M}+0.1 \% \mathrm{hBN}+0.1 \% \mathrm{CNT}+0.69 \% \mathrm{WC}$ (b)

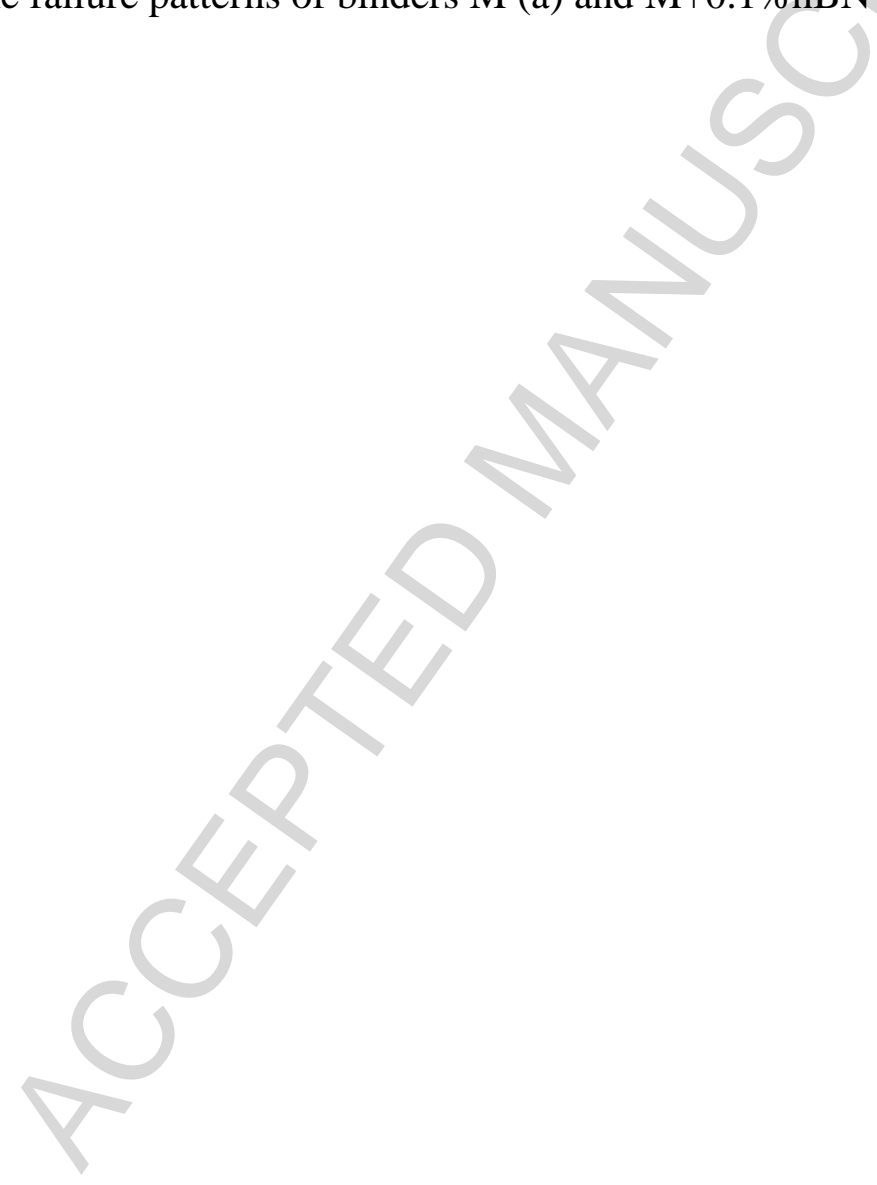




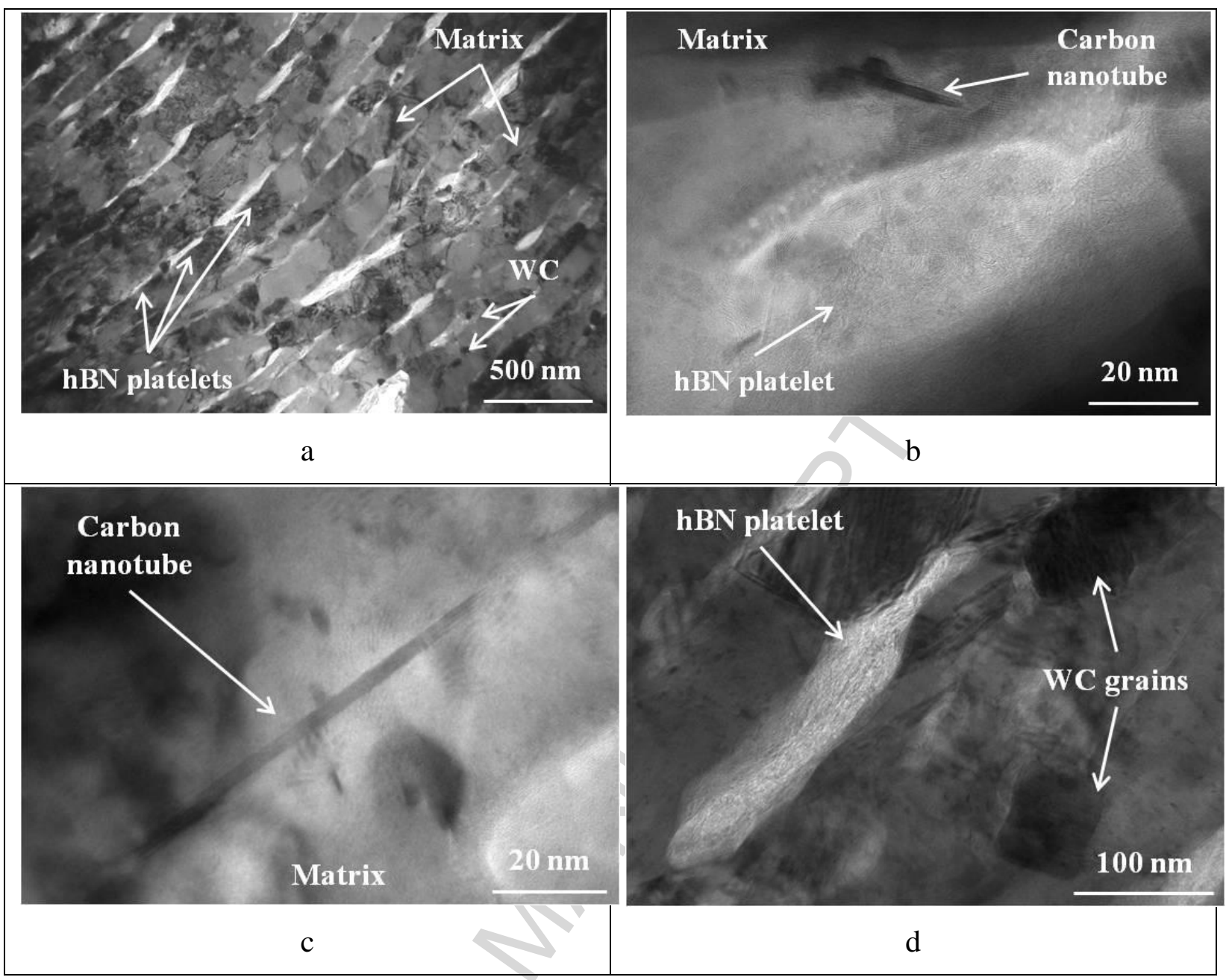

Fig. 4 - High resolution microstructure of hot pressed model sample [80\% $\mathrm{Cu}-20 \% \mathrm{Ni}]-$ $0.1 \% \mathrm{hBN}+0.1 \% \mathrm{MWCNT}+0.69 \% \mathrm{WC}$ (a) and images of $\mathrm{hBN}(\mathrm{b}), \mathrm{CNT}$ (c) and WC nanoparticles (d) 


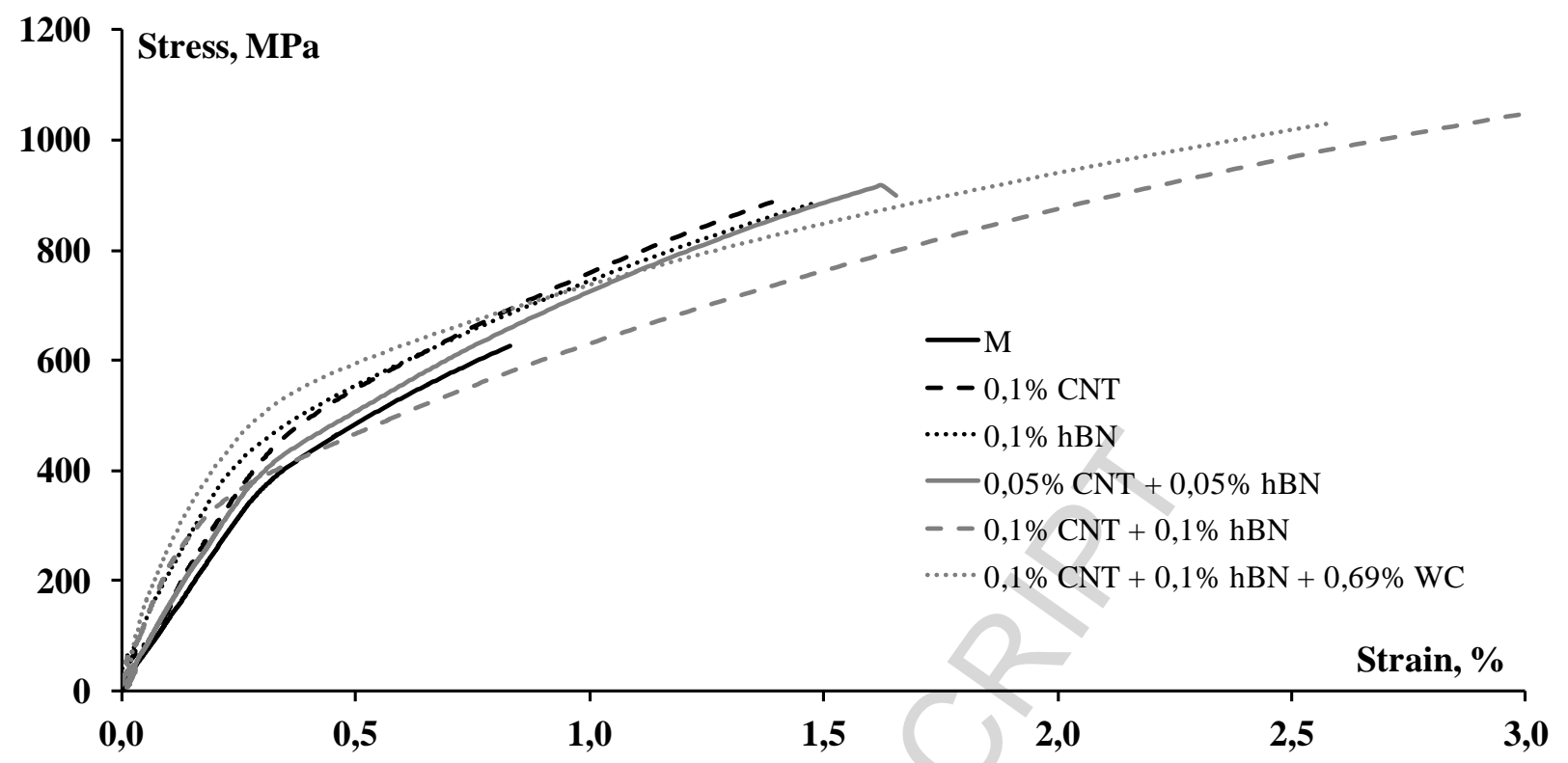

Fig. 5. The stress-strain curves for the initial and nanomodified $M$ binders recorded in the tensile tests 


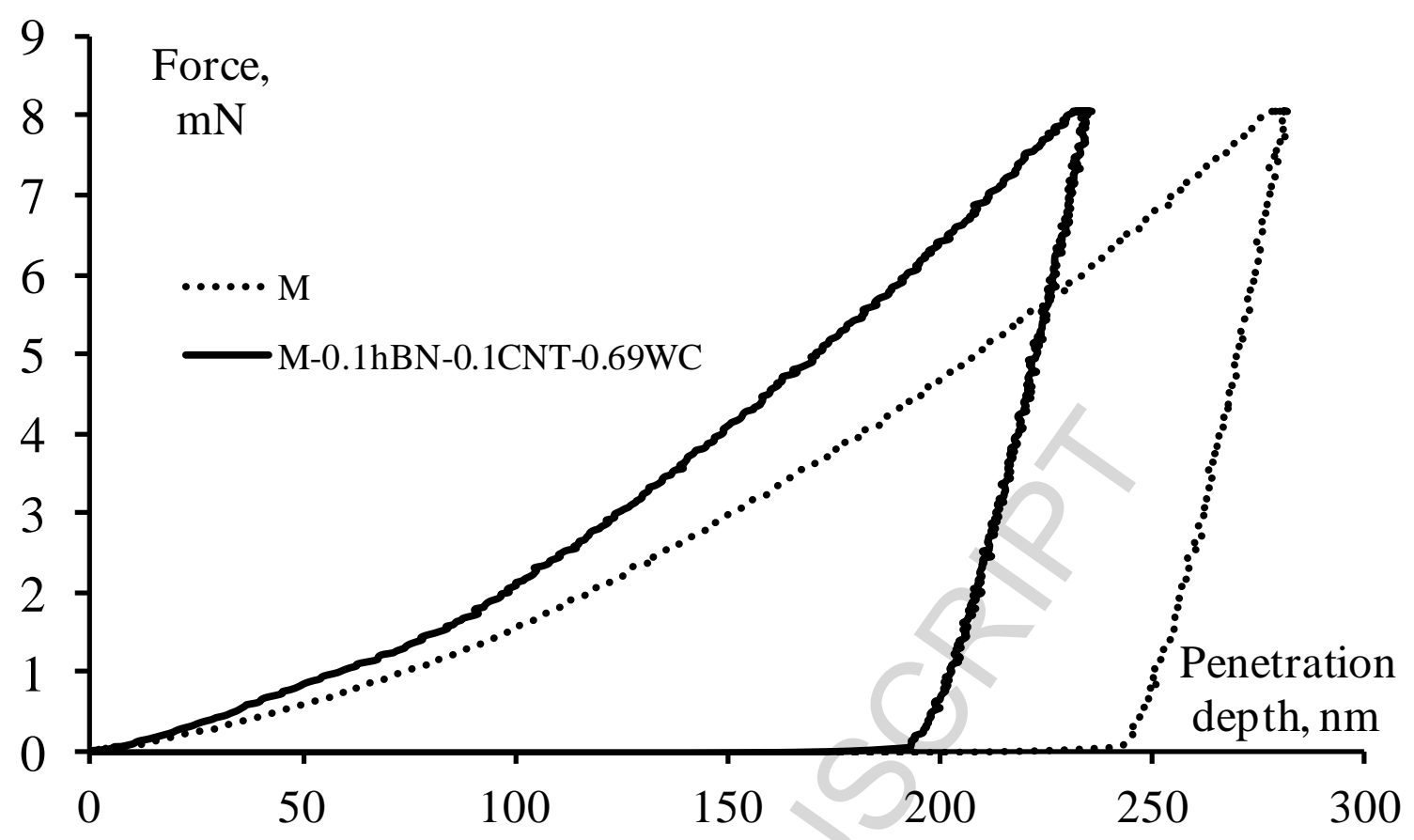

Fig. 6. The typical load-displacement curves recorded upon nanoindentation 
Specific wear,

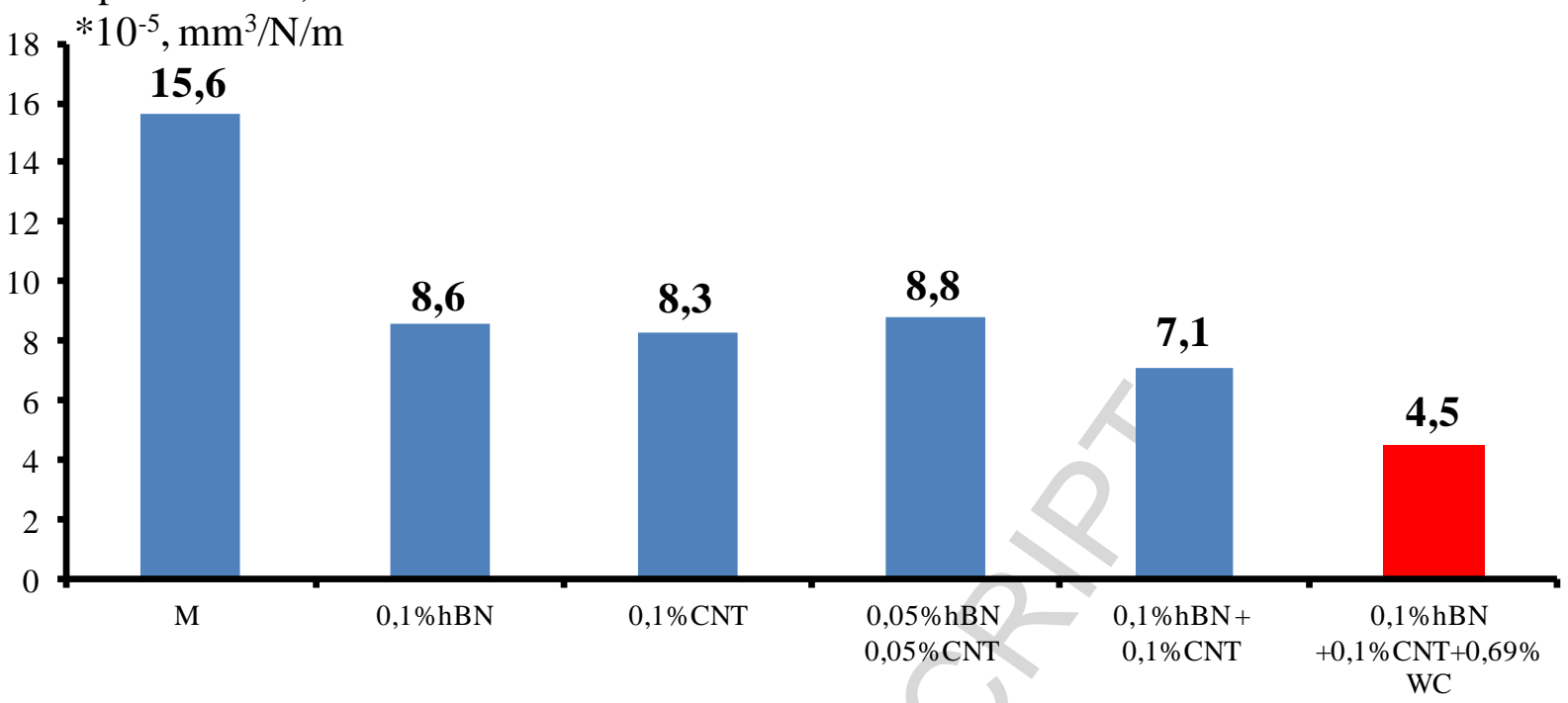

Fig. 7. Specific wear of $M$ binders after tribological tests (sliding tests using a ball made of sintered $\mathrm{Al}_{2} \mathrm{O}_{3}$ as a counter body) 

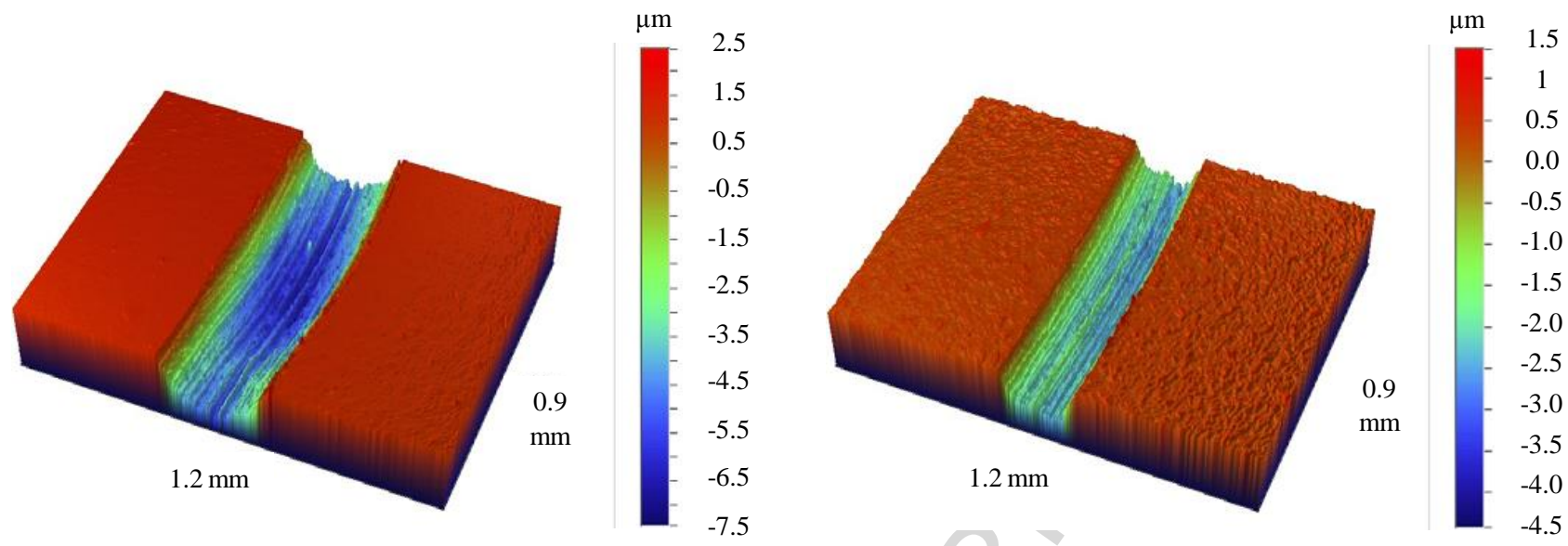

Fig. 8. 3D images of wear track fragments after tribological tests for the samples of binders $\mathrm{M}$ (a) and $\mathrm{M}+0.1 \% \mathrm{hBN}+0.1 \% \mathrm{CNT}+0.69 \% \mathrm{WC}$ (b) 


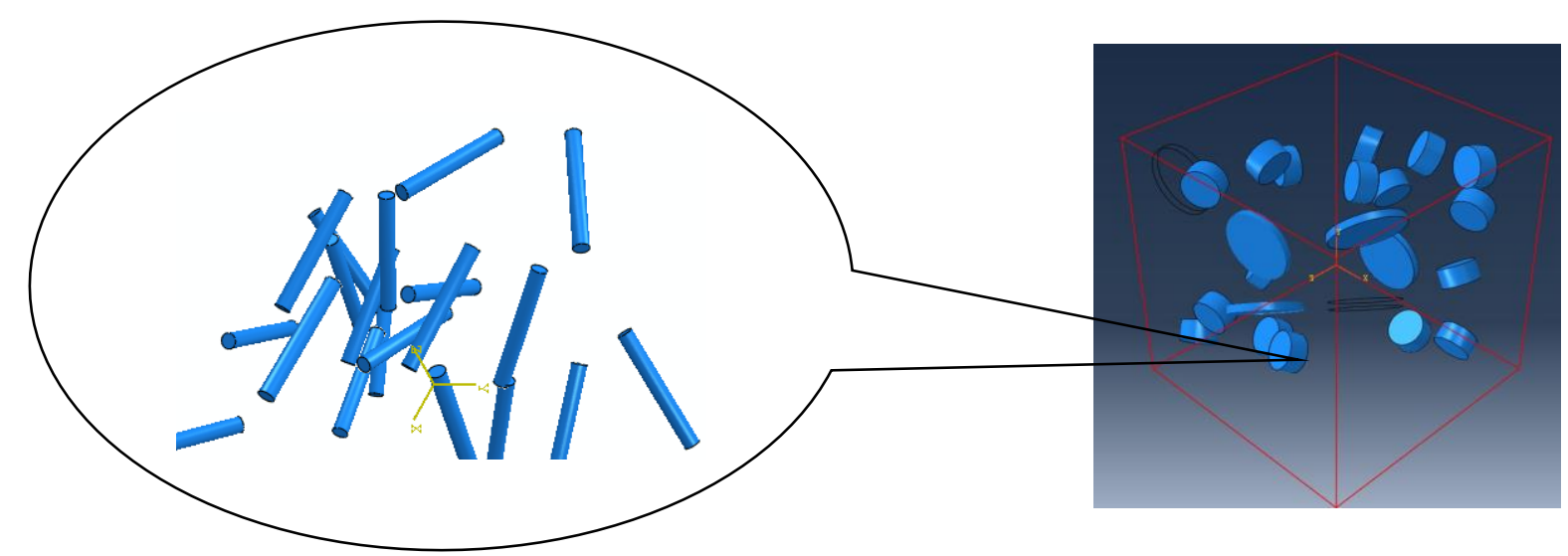

Metal with CNT as low level model

Binder (with CNT) reinforced by hBN and WC (higher level model)

Fig. 9. Multiscale model of hybrid nanoreinforced binder 


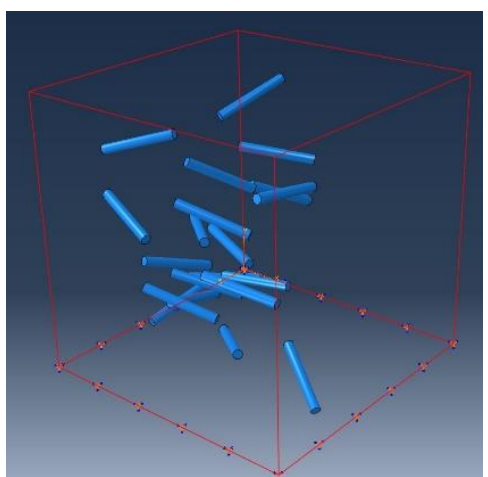

a) Lower level model, metallic matrix plus CNT $0.1 \%$

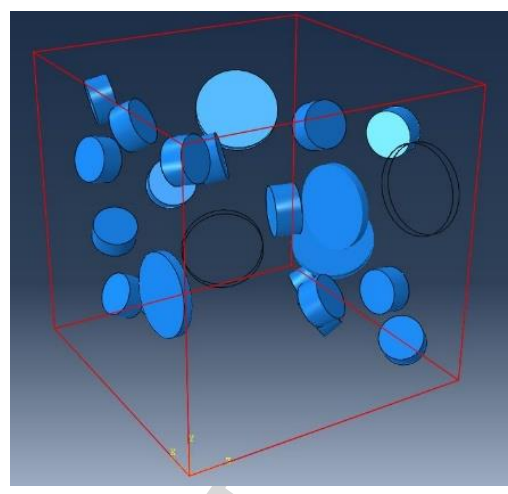

b) Higher level model, with

Fig. 10. Sample unit cells (a) Lower unit cell, and (b) Higher unit cell 


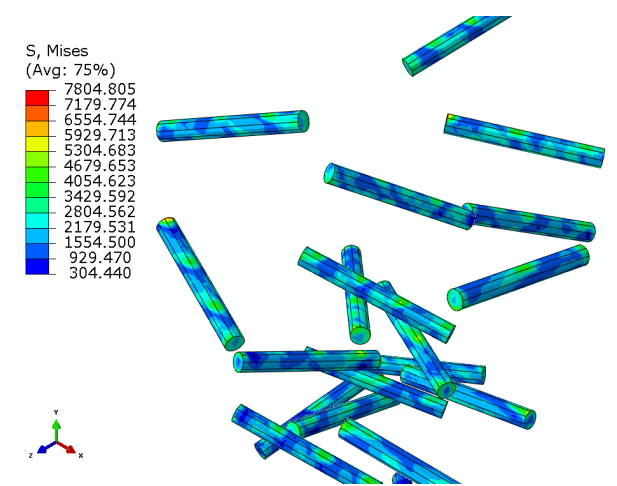

a) Mises stress distribution

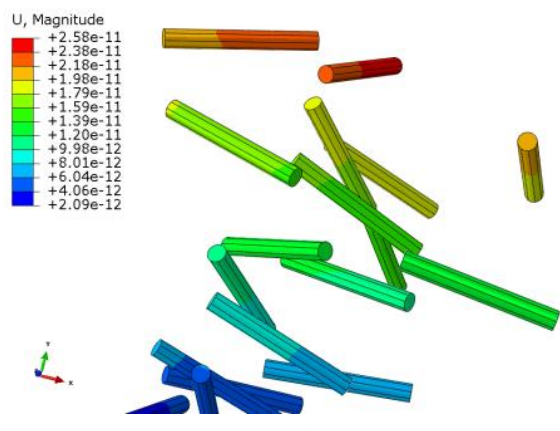

b) Displacemenent in CNT

Fig. 11. Stress and displacement distribution in CNT particles 

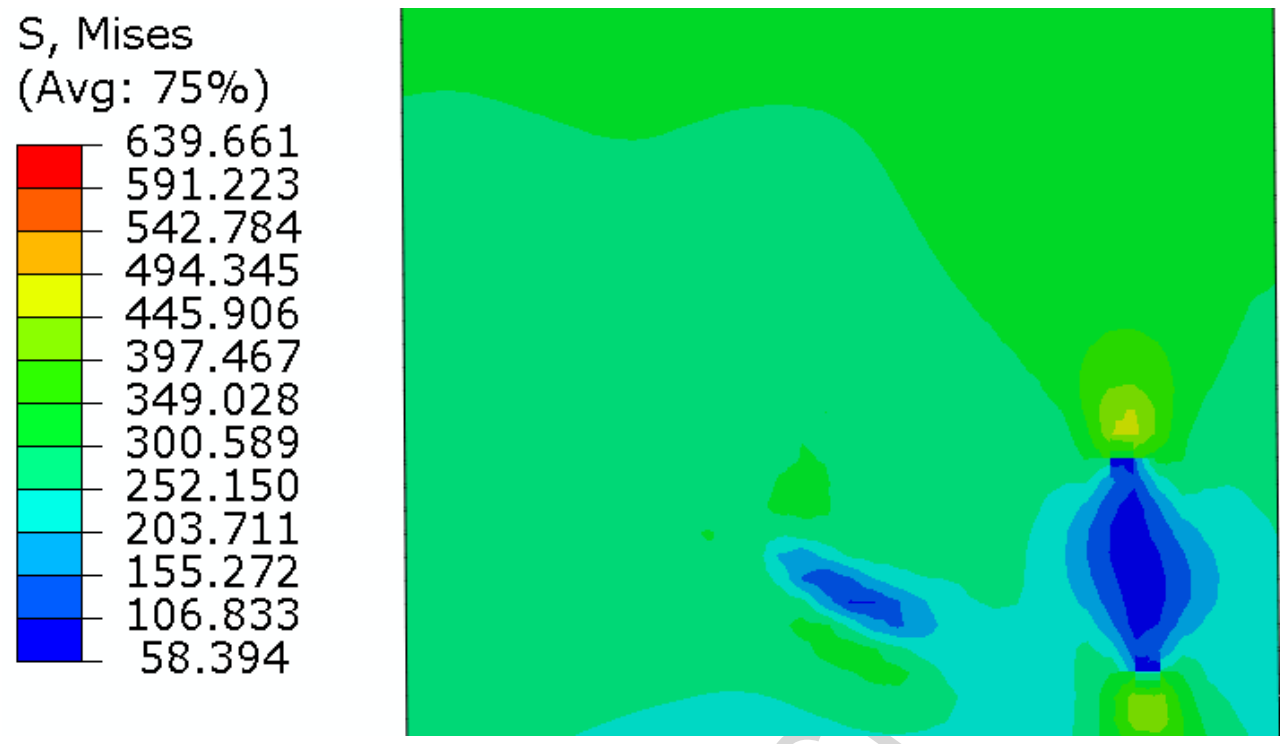

Fig. 12. Stress concentration near the $\mathrm{hBN}$ particles in binder 


\title{
HYBRID METALLIC NANOCOMPOSITES FOR EXTRA WEAR-RESISTANT DIAMOND MACHINING TOOLS
}

\author{
P.A. Loginov ${ }^{1}$, D.A. Sidorenko ${ }^{1}$, E.A. Levashov ${ }^{1}$, M.I. Petrzhik ${ }^{1}$, M.Ya. Bychkova ${ }^{1}$, L. Mishnaevsky Jr. ${ }^{2}$ \\ ${ }^{1}$ National University of Science and Technology “MISIS", Moscow 119049, Russia, \\ ${ }^{2}$ Department of Wind Energy, Technical University of Denmark, Roskilde, Denmark
}

\section{Highlights:}

o Hybrid metallic nanocomposites used as binder in machining tools ensure best performance as compared with virgin binder and single nanoparticle type reinforced binders.

$\circ$ Combining nanoreinforcements of different types and shapes (carbon nanotubes, boron nitride $\mathrm{hBN}$, and WC) results in a 1.5-fold decrease in the grain size of the matrix (if single particles) and by 1.73 -fold (if hybrid particles).

0 The strength of nanocomposites (with CNT+ hBN) is $24 \ldots 26 \%$ higher than that of pure metallic matrix, and for the case pf hybrid nanoreinforcements, the strength is $33 \%$ higher (hBN plus CNT) up to $44 \%$ (all three types of particles).

- Specific wear of the machining tools with these binders is reduced drastically as a result of nanoreinforcements: by $83 \% . . .100 \%$ if the binder is modified by hBN or only CNT or their combination, and by 3.5 times (!) if the binder is modified by all the three types of nanoparticles in combination.

- A multiscale computational model of the nanomodified binder with hybrid reinforcements is developed. 